\title{
DESENVOLVIMENTO LOCAL SUSTENTÁVEL ATRAVÉS DA PRODUÇÃO CONCENTRADA DE MADEIRA EM TORA NO ESTADO DO PARÁ
}

\author{
Gisalda Carvalho Filgueiras'; Maria do Socorro de Lima Caires²; André Cutrim Carvalho³; Ana Cláudia de \\ Sousa Araújo4; Abner Vilhena de Carvalho ${ }^{5}$. \\ ${ }_{1}^{1}$ Professora (Pós-)Doutora da FACECON/ICSA/UFPA, Belém, Pará, Brasil, gisaldaf@yahoo.com.br \\ ${ }^{2}$ Mestre em Economia pelo PPGE/UFPA, Belém, Pará, Brasil, socorrocaires@gmail.com \\ ${ }^{3}$ Professor (Pós-)Doutor da FACECON/ICSA/UFPA e do PPGEDAM/NUMA/UFPA, Belém, Pará, Brasil, \\ andrecc83@gmail.com \\ ${ }^{4}$ Mestranda pelo Programa de Química Medicinal e Modelagem Molecular pela UFPA, Belém, Pará, Brasil, \\ nana22araujo@gmail.com \\ ${ }^{5}$ Doutorando pelo Programa Sociedade, Natureza e Desenvolvimento da UFOPA, Santarém, Pará, Brasil, \\ bnervilhena@hotmail.com
}

RESUMO: A expansão da fronteira agropecuária, no estado do Pará, foi crescente desde os anos de 1960 até o início dos anos de 2000, cujo resultadado foi a luta de classes dos agentes sociais, duradoura, seja do ponto de vista econômico, social, institucional, mas principalmente, ambiental. No ano de 2012, o Pará tornou-se o principal produtor de madeira em tora do Brasil, segundo dados estatísticas do setor extrativo vegetal e de silvicultura. Dada essa produção, o presente trabalho procurou analisar o mercado de madeira a nível mundial, nacional e regional, com destaque para a concentração desse produto em território paraense. Os resultados indicaram a existência de uma produção contínua e, ainda, concentrada em poucos municípios paraenses, tanto através do Índice de Gini Locacional quanto para o Índice de Concentração Normalizado. Portanto, é de grande importância a gestão compartilhada entre atores produtivos locais e a adoção de práticas de desenvolvimento local sustentável - manejo florestal - para que a produção de produtos da madeira continue gerando emprego e renda para o Pará.

PALAVRAS-CHAVE: Desenvolvimento Local Sustentável, Índice de Concentração Normalizado, Índice de Gini Locacional, Madeira em Tora.

\section{SUSTAINABLE LOCAL DEVELOPMENT THROUGH THE CONCENTRATED PRODUCTION OF WOOD IN TORA IN THE STATE OF PARÁ}

\begin{abstract}
The expansion of the agricultural and cattle-raising frontier, in the State of Pará, increased from the 1960s until the beginning of the year 2000, which resulted in a permanent class struggle, from the economic, social, institutional, but mainly environmental, point of view. In 2012, Pará became the main timber producer in Brazil, according to statistics from the extractive sector and forestry. Given this production, the present work sought to analyze the wood market at world, national and regional level, with emphasis on the concentration of this product in Pará territory. The results indicate the existence of continuous production and, still, concentrated in a few municipalities of
\end{abstract}


Pará, both through the Locational Gini Index and the Normalized Concentration Index. Therefore, shared management among local productive actors and the adoption of sustainable local development practices - forest management - are of the utmost importance for the production of wood products to continue generating employment and income for of Pará.

KEYWORDS: Locational Gini Index, Standard Concentration Index, Sustainable Local Development, Timber in logs.

\section{DESARROLLO LOCAL SOSTENIBLE A TRAVÉS DE LA PRODUCCIÓN CONCENTRADA DE MADERA EN TORA EN EL ESTADO DEL PARÁ}

RESUMEN: La expansión de la frontera agropecuaria, en el estado de Pará, fue creciente desde los años 1960 hasta principios de los años 2000, cuyo resultado fue la lucha de clases de los agentes sociales, duradera, desde el punto de vista económico, social, institucional, pero principalmente, ambiental. En el año 2012, Pará se convirtió en el principal productor de madera en tora de Brasil, según datos estadísticos del sector extractivo vegetal y de silvicultura. Dada esta producción, el presente trabajo buscó analizar el mercado de madera a nivel mundial, nacional y regional, con destaque para la concentración de ese producto en territorio paraense. Los resultados indicaron la existencia de una producción continua y, aún, concentrada en pocos municipios paraenses, tanto a través del Índice de Gini Locacional como para el Índice de Concentración Normalizado. Por lo tanto, es de gran importancia la gestión compartida entre actores productivos locales y la adopción de prácticas de desarrollo local sostenible - manejo forestal - para que la producción de productos de la madera continúe generando empleo y renta para el Pará.

PALABRAS CLAVE: Madera en Tora, Índice de Gini Locacional, Índice de Concentración Normalizado, Desarrollo Local Sostenible.

\section{INTRODUÇÃO}

O mercado de madeira em tora, principalmente o mercado de produtos florestais, em geral, incluindo produtos madeireiros e não madeireiros tem sua origem ou matérias-primas oriundas tanto em florestas plantadas como nativas. Os principais produtos não florestais envolvem uma gama de produtos alimentícios (açaí, palmito, outros frutos), além de outras categorias como resinas, tanantes, gomas e cipós. Já os produtos madeireiros possuem maior importância econômica como a madeira em tora, dada a sua utilização como insumo para diversos outros produtos, 
como carvão, lenha, móveis, pontes, celulose e papel, para citar só alguns (IBGE, 2012; 2013). Ademais, para áreas rurais, como explica Fonte e Calil Júnior (2007), a utilização de tabuleiros de madeira laminada protendida em pontes tem-se mostrado ótima alternativa para rodovias rurais ou secundárias, pois, a madeira, ao contrário do que a maioria acredita, é ótimo material estrutural, desde que seja utilizada racionalmente.

Apesar do amplo uso da madeira, enquanto insumo, para Petrauski et al. (2012); Pirraglia et al. (2012), a participação brasileira no mercado internacional de produtos florestais está abaixo do seu potencial, sendo necessário abrir novos mercados para exportação, aumentando, modernizando e assegurando um elevado padrão social e ambiental às atividades florestais, destacado também por Soares e Silva (2013).

Neste contexto, enquanto insumo para outros setores, como a própria construção civil, gráficas e fábricas de artefatos de madeira, existe uma demanda constante e crescente por este produto. Por isto, podem-se citar países de maior tradição na exploração de produtos florestais, com destaque para o Canadá, Alemanha, Estados Unidos, Suécia, Finlândia, Rússia, China, França, Áustria, Indonésia e Brasil. Curiosamente, apenas a Indonésia e o Brasil apresentam parte desta produção baseada em florestas tropicais (ABRAF, 2012; REMADE, 2016). Outro aspecto, diz respeito que a demanda por esse produto é crescente, como por exemplo, em estudo sobre demanda de madeira em tora para a produção de celulose, Angelo et al. (2009), constatou que o preço desta e a capacidade instalada da indústria de celulose, explicam a demanda de madeira em tora com bons resultados econométricos. Entretanto, os estoques de madeiras tropicais (no caso, Indonésia e Malásia) estão rapidamente se esgotando, após décadas de exploração predatória e não manejada.

Deste modo, é natural que o Brasil continue a ser mais pressionado para aumentar as exportações de madeira oriunda da Amazônia, embora haja necessidades de melhor empenho em pesquisas de exploração florestal, ou seja, intensificação no manejo e cultivo 
racional em áreas degradadas para se ter sustentabilidade na exploração e evitar caminhos antes (de destruição) já efetivado por outros países (ABRAF, 2012; SAE/PR, 2014; SOARE; SILVA, 2013). Aliás, - uso da madeira é recomendado porque é um material medianamente combustível e de baixa emissão de fumaça, por isso sua queima libera basicamente água e gás carbônico, dois produtos atóxicos e, segundo Lippke et al. (2011), cada quilo de madeira aplicada em substituição a materiais como alumínio, aço e concreto, reduz, em média, a emissão de 3,9 quilos de $\mathrm{CO}_{2}$.

Em termos de insumo para abastecer indústrias, mundialmente, o mercado de produtos florestais é composto pelo comércio de papel para impressão e para uso de escritório, ainda que tenha se reduzido nos últimos anos; papelões para embalagens e outros fins. Adicionalmente, as madeiras serradas de coníferas são largamente utilizadas na construção civil em conjunto com a própria indústria de mobiliários (SFB, 2013; SAE/PA, 2014; REMADE, 2016).

Em terceiro lugar, na importância de seu uso enquanto insumo tem-se o comércio de polpas celulósicas para a produção de papéis. Na sequência, em quarto e quinto lugar vêm os compensados e madeiras serradas de espécie arbóreas de folhosas que registram $10 \%$ do comércio internacional de produtos florestais, como bem destaca o Serviço Florestal Brasileiro SFB (2013).

Regionalmente, na Amazônia, a expansão da exploração florestal é crescente desde a década de 1960 até o início dos anos de 2000, onde ocorre um embate isolado, de só exploração, sem se preocupar com a reserva de estoques para as futuras gerações. Após diversas reuniões nacionais e internacionais decorrido até mesmo de lutas entre atores econômicos, constatou-se que esta trajetória de apenas retirar a madeira era incompatível com um desenvolvimento sustentável (BRITO et al., 2014; FILGUEIRAS et al., 2011; SANTANA et al., 2010).

Até porque, a exploração de recursos florestais e, portanto, a extração madeireira na Amazônia foi impulsionada pelo crescimento do mercado (interno e externo), do esgotamento das reservas 
da Mata Atlântica, da abertura de rodovias e da expansão da fronteira agrícola (HOMMA, 2011).

Por isto, ações se fizeram necessárias para frear a expansão da fronteira agrícola e de tal modo, melhorar a exploração dos recursos florestais com ênfase a madeira em tora, pois o Pará, ainda em 2012 figurou como o maior explorador, sendo Portel o município da vez. Aliado a esta exploração, tem-se o desmatamento, que vem registrando quedas de forma sistemática, melhorando o controle de órgãos responsáveis por esta tarefa como o Instituto Brasileiro do Meio Ambiente e dos Recursos Naturais - IBAMA, embora não se garanta que ainda a exploração seja legal. Isto é, a produção de madeira na Amazônia, ainda se faz de forma ilegal em sua maioria.

Vale ainda destacar que as produções florestais enfatizam serviços ambientais (abastecimento - produção de água e fonte de alimento; regulação conservação do solo, qualidade do ar e fixação de carbono; apoio - formação do solo, ciclagem de nutrientes; cultural valores estéticos, artísticos e científicos), além de produtos e serviços; produtos não madeireiros diversificados enfatizando seus principais produtos até os segmentos industriais (óleos, essências, etc. - farmacêutico; resinas, solventes, etc. - químico; borracha natural, fibra natural etc. automobilístico; frutos, sementes, cascas, etc. alimentos). Portanto, isso revela a interrelação da cadeia produtiva da madeira com outras indústrias, tanto a montante como em sua manufatura (ABRAF, 2013). Aliás, fato confirmado por vários estudo, como o feito por Santana et al. (2012) no Baixo Amazonas, para estimar o valor econômico e a margem de comercialização da madeira em tora oriunda de áreas manejadas, tendo como conclusão que a cadeia de madeira, além de produzir margem positiva, os valores são relativamente superiores aos gerados nas atividades que concorrem para o desmatamento na Amazônia para se estabelecerem.

Neste contexto, dada a importância do setor florestal para o mundo, Brasil e Amazônia, com destaque ao Pará, este estudo teve como objetivo principal avaliar aonde se concentra a produção 
de madeira no Estado Pará, tendo como base os anos de 1995, 2000, 2005 e 2012. Antes, porém, se visualiza este mercado em nível mundial, nacional e regional.

\section{MATERIAL E MÉTODO}

método aqui adotado consiste em trabalhar com o instrumental estatístico proveniente da análise multivariada. Para isso foi necessário à utilização de três métodos de cálculos que serão os principais indicadores. Neste aspecto, Crocco et al. (2006), citado por Santana et al. (2010) desenvolveram um índice de concentração que evita as distorções provocadas por valores absolutos do quociente locacional (QL).

Nesta seção se expõe a metodologia do ICN tendo como variável o Valor Bruto da Produção (VBP) do Estado do Pará. O Pará foi escolhido, conforme anteriormente explicado, por ser extrativismo vegetal, apenas a madeira em tora, como base fornecedora de insumos para as indústrias de papel e celulose.

Sendo assim, partiu-se de informações essenciais, utilizando como dados variáveis O VBP para identificar os municípios especializados na produção desse insumo. Para tanto, foram utilizadas as variações do valor bruto da produção - extrativa- de madeira relativo aos anos de 1995, 2000, 2005 e 2012 na construção do ICN, obtidas junto ao Instituto Brasileiro de Geografia e Estatística-IBGE (2012; 2013).

O Pará, com uma superfície de $1.248 .042 \mathrm{~km}^{2}$, representa $15 \%$ do território nacional, possui grande potencial madeireiro, é considerado o maior produtor de madeira em tora com uma quantidade obtida de $4.877 .005 \mathrm{~m}^{3}$ no exercício de 2012 (IBGE-PEVS, 2012). Entretanto, na maior parte dos casos, a exploração florestal no Estado tem ocorrido de forma desordenada provocando danos significativos à vegetação, como é o caso da utilização da madeira como combustível na forma de carvão vegetal, destacando como maior produtor o município de Itupiranga, com 15.200 toneladas, equivalente a $3.150 .592 \mathrm{~m}^{3}$, com participação relativa de 1,3 e acumulada em 29,2 (IBGE, 2012).

Foram utilizadas diversas fontes de informações. Os dados estatísticos como 
as séries históricas da produção, no período de 1995 a 2012, obteve-se junto à Produção Extrativa Vegetal e da Silvicultura (PEVS, 2012), do Instituto Brasileiro de Geografia e Estatística (IBGE, 2012; 2013).

Além disso, realizou-se uma ampla revisão bibliográfica em periódicos especializados, artigos, sites e, por fim, procedeu-se o cálculo do Índice de Gini Locacional (IGL) e do Índice Concentração Normalizado (ICN) para saber quais municípios são especializados na produção de madeira em tora, nos quatro anos pesquisados (1995, 2000, 2005 e 2012).

O índice Gini foi calculado conforme proposto por Hoffmann (2006), enquanto o do ICN é semelhante aos trabalhos descritos por Crocco (2003) ambos citados por Santana et al (2010). Na sequência se descreve a referida metodologia, tendo variável base de cálculo para o ICN, o Valor Bruto da Produção Florestal (VBP-F) no Estado do Pará e seus respectivos municípios no período acima destacado. Recentemente, Lima e Esperidião (2014) aplicaram índices de concentração para regiões brasileiras em anos alternados, confirmando amplo uso desses índices. Aliás, estudos diversos tem sido feitos para ver a concentração e, portanto, poder de mercado, como o feito recentemente por Chiapinoto el al. (2017) sobre o setor de telefonia móvel, cujo método foi baseado na aplicação do Índice de Concentração Herfindahl Hirshman $(H H)$ e da Razão de Concentração CR(4).

O Pará foi escolhido por possuir a maior quantidade de floresta nativa e ser considerado o maior produtor de madeira em tora do país e do Norte, em 2012. Os dados da pesquisa são secundários, como VBP, produção, importação e consumo foram obtidos junto ao Instituto Brasileiro de Geografia e Estatística (IBGE), Food and Agriculture Organization of the United Nations (FAO) e Associação Brasileira de Produtores de Florestas Plantadas (ABRAF). Ressalte ainda, que Esquivel et al. (2012, p. 88), expões que: "o desenvolvimento de métodos estatísticos para análise de dados obtidos em situações em que as observações são dependentes tem 
apresentado crescimento vertiginoso nas últimas décadas".

MODELO ANALÍTICO: CÁlCULOS DOS ÍNDICES DE CONCENTRAÇÃO

Os indicadores, segundo Polder et al. (2009), facilitam uma intuição ao recorrerem a dados objetivos para aferir uma situação de maior ou menor concorrência em um dado mercado. 0 cálculo do ICN teve como variável o VBP, do Pará. Este Estado foi escolhido, como anteriormente explicado, por ter o extrativismo vegetal (apenas a madeira em tora) como base fornecedora de insumos para as indústrias de papel e celulose. Assim, partiu-se de informações essenciais, utilizando como dados variáveis O VBP para identificar os municípios especializados na produção desse insumo, utilizando as variações do VBP - extrativa- de madeira relativo aos anos de 1995, 2000, 2005 e 2012 na construção do ICN, obtidas junto ao IBGE (2012; 2013).

Índice de especialização ou quociente locacional (QL) - Este índice serve para definir se um município em particular possui especificação em dada atividade ou setor específico que é calculado com base na razão entre dois mecanismos econômicos.

$$
\mathrm{Q} L=\frac{E_{\mathrm{ij}} / E_{j}}{E_{\mathrm{iP}} / E_{P}}
$$

Em que: $E_{i j}$ é o VBP da atividade ou setor i no município em $E_{i p}$ estudo j: $E_{j}$ é o VBP referente a todas as atividades que fazem parte no município j: é o VBP da atividade ou setor i no estado do Pará; $E_{p}$ é o VBP de todas as atividades extrativas ou setores no Pará.

\section{Índice de concentração de Hirschman-} Herfindahl $(\mathrm{IHH})$ - Usado para captar o real peso da atividade ou setor na estrutura produtiva local. Este indicador é uma modificação do índice, definido da seguinte forma:

$$
I H H=\frac{E_{i j}}{E_{i p}}-\frac{E_{i}}{E_{p}}
$$

O $\mathrm{HH}$ permite comparar o peso da atividade ou setor i do município j no setor i do estado do Pará em relação ao peso da estrutura produtiva do município j na estrutura do estado como um todo. Nestes termos, um valor positivo indica que a atividade ou setor i do município j no Pará está ali, mais centralizado e, portanto, com maior poder de atração 
econômica, dada sua particularização em tal atividade ou setor.

Índice de participação Relativa (PR) - Este indicador que foi utilizado para entender a importância da atividade ou setor $\mathbf{i}$ do município j diante do total do VBP na mencionada atividade para o estado do Pará. A fórmula é dada por:

$$
P R=\begin{aligned}
& E_{i j} \\
& E_{i p}
\end{aligned}
$$

Este número varia entre zero e um. Quanto mais próximo de um maior a importância da atividade ou setor i do município j no estado do Pará.

\section{Índice de Concentração Normalizado}

(ICN) - Os indicadores descritos fornecem os insumos básicos para a construção de uma referência mais geral e consistente de agrupamento empresarial ligado a uma atividade ou setor econômico em um município, denominado de ICN e, este, é dado pela seguinte fórmula:

$$
I C N_{i j}={ }_{1} Q L_{i j}+{ }_{2} I H H_{i j}+{ }_{3} P R_{i j}
$$

Em que os pesos de cada um dos indicadores para cada atividade ou setor produtivo em análise. Para o cálculo dos pesos de cada um dos índices explicitados na equação, 4 empregou-se o método da análise de componentes principais.

\section{Modelo de Componentes Principais - 0} modelo de componentes principais com $m$ e componentes $p$ variák $(3)$ ) $(q>p)$, pode ser escrito como na equação seguinte:

$$
\begin{aligned}
& \boldsymbol{C} \boldsymbol{P}_{1}={ }_{11} \boldsymbol{X}_{1}+{ }_{12} \boldsymbol{X}_{2}+\cdots+{ }_{1 p} \boldsymbol{X}_{p} \\
& \boldsymbol{C} \boldsymbol{P}_{\mathbf{2}}={ }_{21} \boldsymbol{X}_{\mathbf{1}}+{ }_{22} \boldsymbol{X}_{\mathbf{2}}+\cdots+{ }_{2 \mathrm{p}} \boldsymbol{X}_{\boldsymbol{p}} \\
& \boldsymbol{C} \boldsymbol{P}_{q}{ }_{\mathrm{q}}={ }_{\mathrm{m} 1} \boldsymbol{X}_{\mathbf{1}}+{ }_{\mathrm{m} 2} \boldsymbol{X}_{\mathbf{2}}+\cdots+{ }_{\mathrm{qp}} \boldsymbol{X}_{\boldsymbol{p}}
\end{aligned}
$$

Em que:

$C P_{\mathrm{i}}=$ são as i-ésimas componentes principais $(i=1,2 \ldots q)$;

ij= são os coeficientes relacionados para cada variáveis;

$X_{j}=$ são os j-ésimas variáveis $(j=1,2 \ldots . p)$.

Cálculo do peso para o ICN - Seguindo a metodologia descrita por Santana (2010), os cálculos dos pesos iniciam com os resultados dos autovalores ou variâncias relativas em todos os componentes principais da variância acumulada, como 
descrito na Tabela 1. Logo, CP1 significa o

total que é explicada por esse autovalor do primeiro componente componente e assim, sucessivamente.

principal ou a proporção da variância

Tabela 1. Autovalores da matriz de correlação ou variância explicada pelos componentes principais, a partir da matriz variância-covariância.

\begin{tabular}{lcc} 
Componente principal Variância explicada & Autovalores & $\begin{array}{c}\text { Proporção da } \\
\text { variância }\end{array}$ \\
\hline Componente $C P_{1}$ & 1 & 1 \\
Componente $C P_{2}$ & 2 & $1+2$ \\
Componente $C P_{3}$ & 3 & $1+2+3$ \\
\hline
\end{tabular}

Fonte: Santana (2005, p.135).

A Tabela 1 fornece a variância dos dados referentes a cada componente principal, também. Além disso, o peso final que se atribui a cada indicador específico é dado pelo acordo linear dos produtos dos coeficientes pelos correspondentes autovalores relativos, a cada componente principal como a seguir.

$$
\begin{gathered}
i=(i i j=1, \ldots, 3) f i j \\
(i i=1, \ldots, 3)
\end{gathered}
$$

Tabela 2. Matriz de coeficientes, pesos ou dos autovalores da matriz de correlação

\begin{tabular}{lccc}
\hline Indicador de insumos & Componente $C P_{1}$ & Componente $C P_{2}$ & Componente $C P_{3}$ \\
\hline $\mathrm{QL}$ & 11 & 12 & 13 \\
$\mathrm{HH}$ & 21 & 22 & 23 \\
$P \mathrm{R}$ & 31 & 32 & 33 \\
\hline Soma dos coeficientes & 1 & 2 & 3 \\
\hline
\end{tabular}

Fonte: Santana (2010).

Tem-se a matriz de coeficientes ou linear simples e com esses dados é dos autovalores da matriz de correlação possível calcular a participação relativa 
de cada um dos indicadores em cada um dos componentes principais. O cálculo é feito da seguinte forma:

10) Obtém-se a soma dos valores absolutos dos autovetores associados em todos os componentes $(\mathrm{iij}=1, \ldots, 3=\mathrm{ij})$ verificando que o sinal negativo de algum autovetor está apenas indicando que está atuando no sentido oposto ao dos demais dentro de cada componente principal;

$2^{\circ}$ ) Divide-se o valor absoluto de ii cada autovetor ij pela soma i associada a cada componente, gerando a matriz de autovalores recalculados $f_{i j}=(|i j| / i)$, conforme a Tabela 3:

Tabela 3. Matriz de participação relativa dos indicadores em cada componente principal.

\begin{tabular}{|c|c|c|c|}
\hline Indicador de insumo & Componente $C P_{1}$ & Componente $\mathrm{CP}_{2}$ & Componente $\mathrm{CP}_{3}$ \\
\hline QL & $f_{11}=\left(\left.\right|_{11} \mid /{ }_{1}\right)^{1}$ & $f_{12}=\left(\left.\right|_{12} \mid / 2\right)^{2}$ & $f_{13}=\left(||_{13} \mid /{ }_{3}\right)^{3}$ \\
\hline $\mathrm{HH}$ & 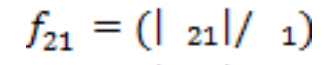 & $f_{12}=\left(\begin{array}{ll}\mid & 22\end{array} /{ }_{2}\right)$ & $f_{23}=\left(\left.\right|_{23} \mid /{ }_{3}\right)$ \\
\hline$P \mathrm{R}$ & $f_{31}=\left(\left|{ }_{31}\right| /{ }_{1}\right)$ & $f_{12}=\left(\left.\right|_{31} \mid /{ }_{2}\right)$ & $f_{33}=\left(\left.\right|_{23} \mid /{ }_{3}\right)$ \\
\hline
\end{tabular}

Fonte: Santana (2010).

Considerando que a soma dos pesos é igual a um, torna-se factível que as combinações lineares dos indicadores na forma padronizada contribuem para gerar o índice de concentração normalizado (ICN), em que os coeficientes são os próprios pesos calculados pelo método dos componentes principais, de acordo com o especificado na Equação 4.

\section{RESULTADOS E DISCUSSÃO}

O MERCADO INTERNCIONAL DE MADEIRA E SEUS DERIVADOS
A cadeia produtiva do setor florestal (Figura1), mostra a importância estratégica da mesma na economia, seja em nível nacional como internacional. Esta configuração da cadeia mostra o inter-relacionado de produtos florestais e não florestais que podem abastecer, enquanto insumo, um número significativo de outras atividades, que podem derivar tanto da floresta plantada como nativa. Percebe-se maior diversificação para os produtos madeireiros, mas, apesar da importância das florestas plantadas de pinus e eucalipto como principal insumo para a indústria de celulose e outros produtos, o 
mercado de madeira em tora, seja para celulose ou para outros fins, tem sido pouco estudado no Brasil, nas afirmações de Angelo et al (2009).

$\mathrm{Na}$ verdade, trata-se de um importante mercado que gera divisas, emprego e renda, amplamente discutido por diversos autores, dos quais destacam-se mais recentemente Santana et al (2010); Filgueiras et al (2011), SFB/IMAZON (2011) e SAE/PR (2014). Portanto, a utilização da madeira em grande escala se deve a razão entre a sua qualidade por ser resistente e seu peso que são elevados, por isso é um excelente material para construção, possui resistência e solidez que são fundamentais para estruturas que necessita de durabilidade. Além disso, a madeira tem uma facilidade de ser beneficiada e comercializada. Suas transformações em diversos objetos exigem um trabalho artesanal como o de móvel, instrumentos musicais, artigos de arte e painéis que são trabalhos em madeira (REMADE, 2016; REFLORE, 2013; FAO, 2012; 2009).

O produto madeireiro tem uma participação muito importante na economia dos países, que tem a produção de madeira em tora como uma de suas fontes de recursos naturais. E, caracteriza-se pela grande diversidade de uso compreendendo um conjunto de atividades industriais (processamento mecânico, siderurgia a carvão vegetal, energia) que incluem desde a produção até a transformação da madeira em produtos finais (ABRAF, 2013).

Nesse sentido, conforme expõe a Secretaria de assuntos estratégicos, da Presidência da República (SAE/PR, 2014), A produção e os serviços advindos do setor florestal são importantes para amparar qualquer tipo de processo de desenvolvimento, seja em nível local, regional ou global.

A percepção da sociedade sobre essa realidade é cada vez mais clara, e o desafio consiste em garantir que essa extensão de floresta dita patrimônio natural possa ser sempre a fonte que gera benefícios aos seres humanos e ao mundo de maneira sustentável. Por outro lado, sabe-se que as florestas (nativas e plantadas) ocupam aproximadamente $31 \%$ da superfície terrestre, sendo que participarem com apenas $7 \%$ do total 
dessa área, as florestas plantadas exercem um papel relevante nas estratégias de conservação (ABRAF, 2013).

Dados da FAO revelam que as florestas plantadas cobrem uma área de 264 milhões de hectares com expansão em média de 5 milhões de hectares por ano, cuja estimativa variam entre 1/3 e 2/3, respectivamente, da demanda global de madeira em tora para fins industriais (EFIATLANTIC, 2013).
Isto é importante de destacar, porque o uso da floresta nativa tem sido muito combatido da forma de apenas the explorá-la, sem preocupações de garantir estoque para futuras gerações. Sendo assim, o crescimento do incentivo a floresta plantada é um resultado previsível e requerido nos momentos recentes (REMADE，2016; ABRAF, 2013; IBGE, 2012/2013).

Figura 1. Possibilidades de inter-relação da cadeia produtiva do setor florestal

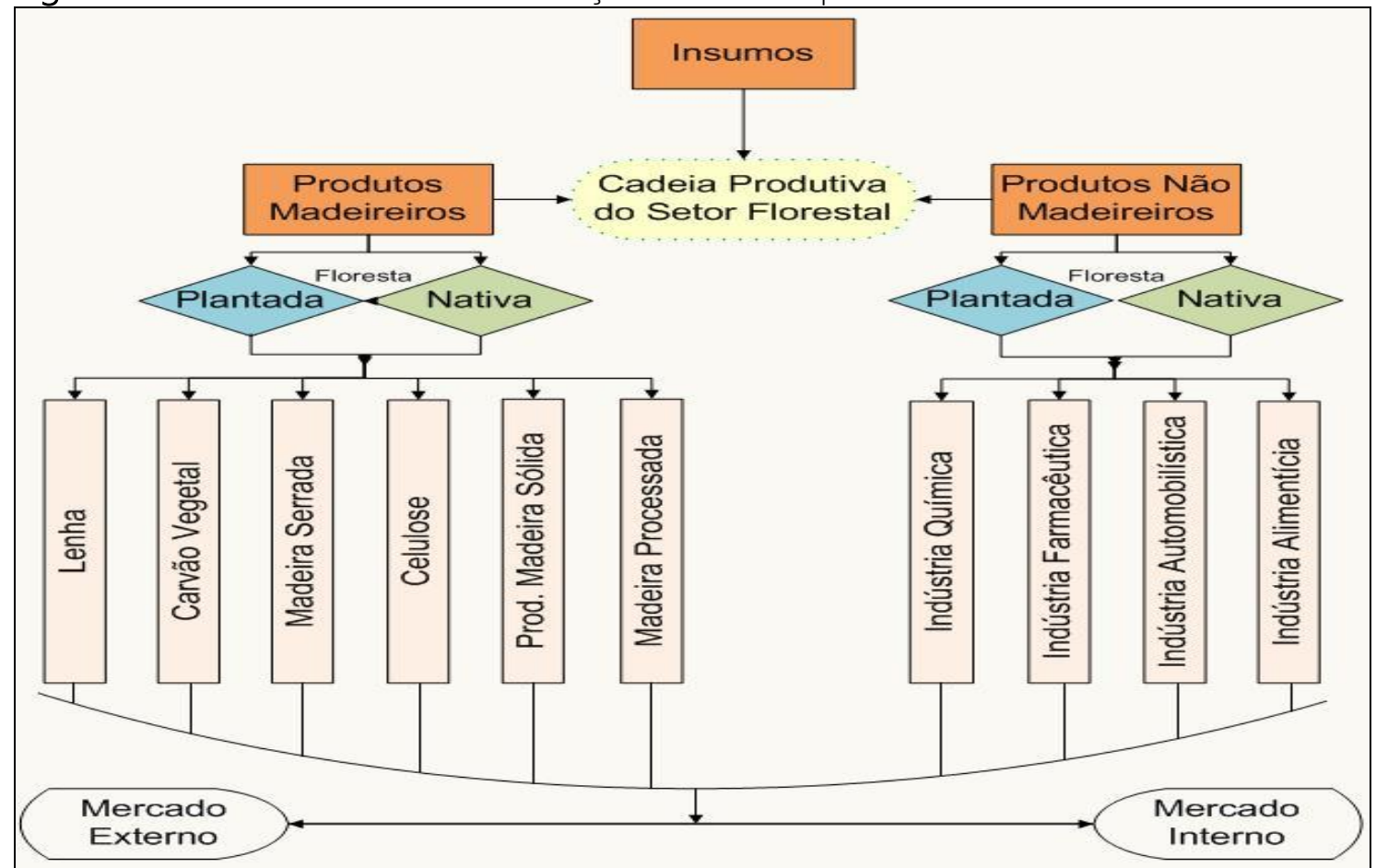

Fonte: Sistema Nacional de Informações Florestais - snif/producao-florestal/cadeia-produtiva. Disponível: < http://www.florestal.gov.br/snif/producao-florestal/cadeia-produtiva>. Acesso: mar/2017. 
Ainda informação da ABRAF (2013), relativo a 2012, mostra os segmentos da indústria brasileira de base florestal associada às florestas plantadas registraram crescimento das exportações e do consumo interno, com exceção da celulose cuja produção foi inferior ao ano de 2011. Destaca, ainda, os principais países importadores dos produtos, tais como: Argentina, a Alemanha e a China, que lideraram o ranking da importação de papel, compensados e celulose, sendo a China a maior importadora do produto respectivamente.

De outro lado, os Estados Unidos lideraram a importação de painéis e madeira serrada. Para atender a demanda mundial, foi exportado em dólar americano USD 678,7 milhões tendo como principal exportador a Europa (Holanda 20,9\%), Hungria (9,4\%), Grã-Bretanha (5,6\%), França (3,7\%), China (26,3\%), Estados Unidos (19,3\%) (REMADE, 2016; ABRAF, 2013). Observase pelos dados da ABRAF (2013), que o saldo total das exportações brasileiras alcançou a cifra de USD 242,6 bilhões, representando uma queda de 5,2\% em relação a 2011 (USD 256,0 bilhões).
As importações diminuíram 1,4\% em relação a 2011, totalizando USD 223,1 bilhões. Nesse contexto o saldo da balança comercial brasileira de 2012 foi positivo em USD 19,5 bilhões, embora tenha diminuído 34,6\% em relação a 2011.

O saldo da balança comercial referente à atividade florestal registrou superávit de USD 5,5 bilhões em 2012. Entretanto devido à queda das exportações em 2012, o saldo da balança comercial sofreu declínio de 3,5\% em relação ao apresentado no ano de 2011. As exportações totalizaram USD 7,5 bilhões e registraram uma queda de 6,2\% em relação ao ano anterior (REMADE, 2016; ABRAF, 2013).

Da mesma forma, as importações sofreram queda de 9,1\% em relação a 2011, totalizando USD 2,0 bilhões. Ressalta-se que a queda dos preços impactou as exportações de 2012, visto que a quantidade exportada ficou ligeiramente acima de 2011, conforme demonstrado na Figura 2. 
Figura 2. Saldo da Balança Comercial de Produtos florestais plantadas

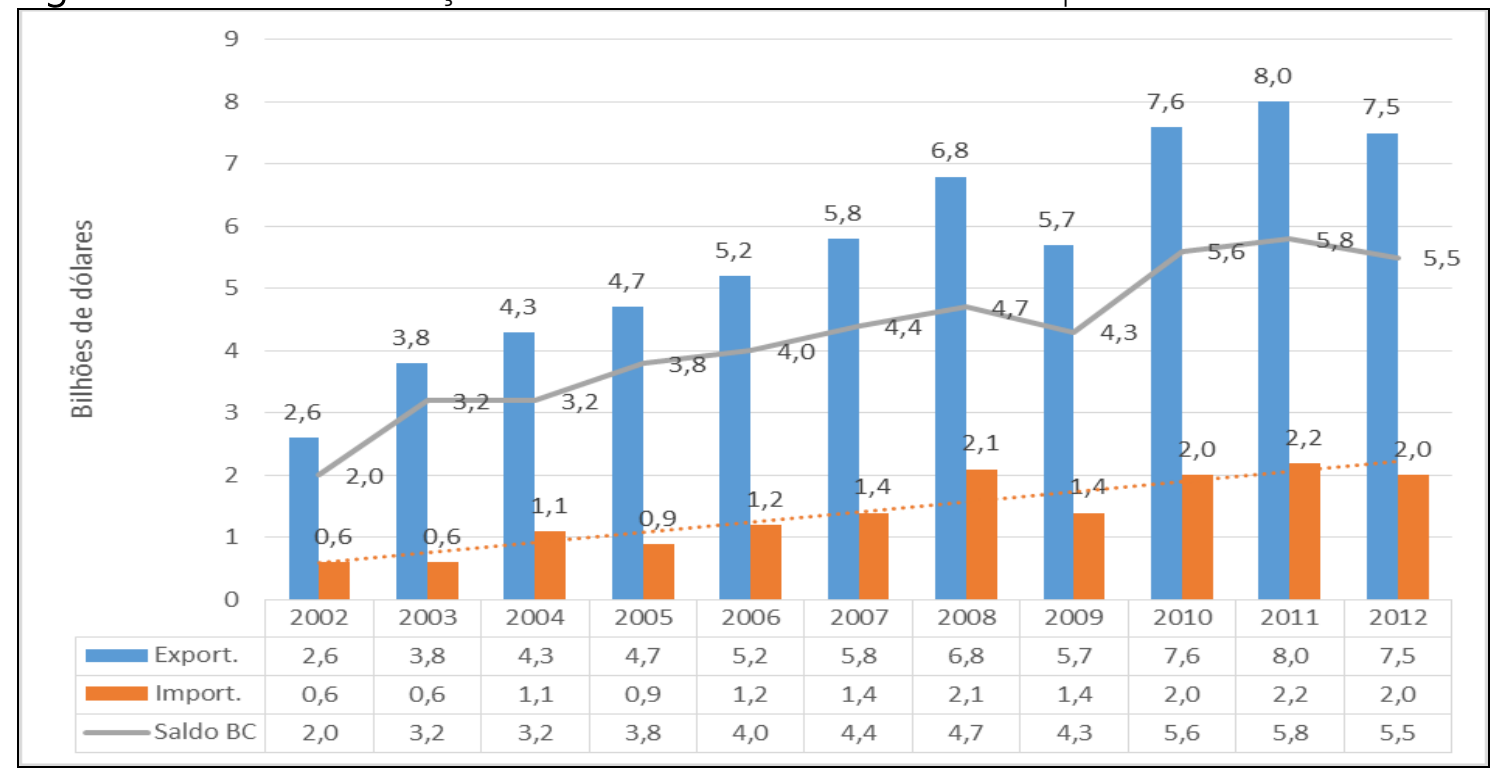

Fonte: Elaboração própria a partir dos dados da SECEX, disponibilizados pela ABRAF, ano 2013.

Por fim, o panorama da produção mundial de madeira para todos os fins aproxima-se de 3,5 bilhões de metros cúbicos por ano. E os países produtores são: Estados Unidos, China, Índia, Brasil, Indonésia e Canadá produzem mais da metade de toda a madeira do mundo. $\mathrm{O}$ Brasil é o quarto maior produtor mundial de madeira, participando com seis por cento do total produzido. A maior parte da produção mundial é de biomassa para uso energético, ou seja: lenha e carvão vegetal (ABRAF, 2013, IBGE-PEVS, 2012/2013).

Em nível beneficiamento, próximo de 1,5 bilhão de metros cúbicos de madeira são destinados à transformação industrial: processamento mecânico
(60\%), papel e celulose (27\%) e fabricação de painéis reconstituídos (3\%) (ADVFN, 2014). Ainda pela mesma fonte, sabe-se que: A União Européia, os Estados Unidos e o Japão são os grandes consumidores de produtos florestais. Implica dizer, que o setor movimenta, em termos de comércio mundial (importações mais exportações) de madeira e derivados, cerca trezentos bilhões de dólares por ano.

Ainda, o Canadá, sozinho, responde por $20 \%$ do valor total exportado e, se considerar os cinco maiores exportadores, os mesmos respondem por mais da metade das exportações mundiais (Canadá, Estados Unidos, Finlândia, Suécia e Alemanha). Tudo isto 
dá a dinâmica do setor florestal, em nível internacional.

De qualquer modo, o Brasil, assim como os países de madeira tropical, tem que se adaptar a um novo modo de produção, pois os próprios consumidores não estão dispostos a comprar madeira de produção sustentável. Tanto assim que, em 2001, o Japão - um dos maiores consumidores e importador de produtos florestal, no caso madeira, já dava recados claros, qual seja: o governo do Japão anunciou que vai adotar medidas concretas para impedir a entrada de madeira ilegal no mercado japonês.

O Japão é um dos maiores importadores de madeira do mundo em particular de madeira vinda do Sudeste da Ásia e da Amazônia (GREENPEACE， 2001). Para o Ministro daquele país, Sr. Matsuoka anunciou: "Como país consumidor, nós não deveríamos ajudar a destruição ambiental", disse o ministro ao jornal "Asahi Shinbun". Até agora, o Japão considerava que a responsabilidade de combater a madeira ilegal era dos países produtores.

\section{A EXPLORAÇÃO DE MADEIRA EM TORA NO BRASIL E DEMAIS REGIÕES}

No Brasil, verifica-se que o país possui uma das maiores áreas florestal com 463 milhões de hectares ou 54,4\% da área do país (IMAZON-SFB, 2013). Destes, sete milhões de hectares correspondem a florestas plantadas (menos de 1\% da área do País). Essa pequena área é capaz de prover quase $90 \%$ do total da oferta de madeira em tora industrial, 81,5\% do carvão vegetal e $62,3 \%$ da lenha produzida internamente, conforme demonstra a Figura 3, segundo o IBGE (2013).

No nível de contribuição econômica, para o País é relevante não apenas do ponto de vista de abastecimento do mercado interno. Ao se considerar as exportações do agronegócio em 2013, os produtos florestais estão entre os quatro mais importantes, com 10\% do valor total, atrás apenas dos complexos, soja (31\%), carne (17\%) e sucroalcooleiro (14\%). Vale ressaltar que o agronegócio brasileiro respondeu por $41 \%$ do total das exportações brasileiras em 2013, chegando a quase US\$ 100 bilhões, segundo dados da ABRAF (2013). 
Apesar das estatísticas favoráveis do setor, o país ainda tem muito a desenvolver e aproveitar seu potencial econômico. Embora, a participação de produtos florestais brasileiros represente menos de 3\% do comércio anual internacional, este supera o valor de US\$ 230 bilhões conforme dados da FAOSTAT (2014).
Se observar de maneira segmentada o setor, é possível perceber uma forte diferença em termos de competitividade internacional. No caso da celulose, o Brasil ocupa $04^{\circ}$ produtor mundial, tendo alcançado em 2012 cerca de14\% do comércio mundial, que foi de US\$ 30,6 bilhões.

Figura 3. Percentual das florestas plantadas e do extrativismo vegetal na produção de madeira em tora, carvão vegetal e lenha no Brasil 2011-2012

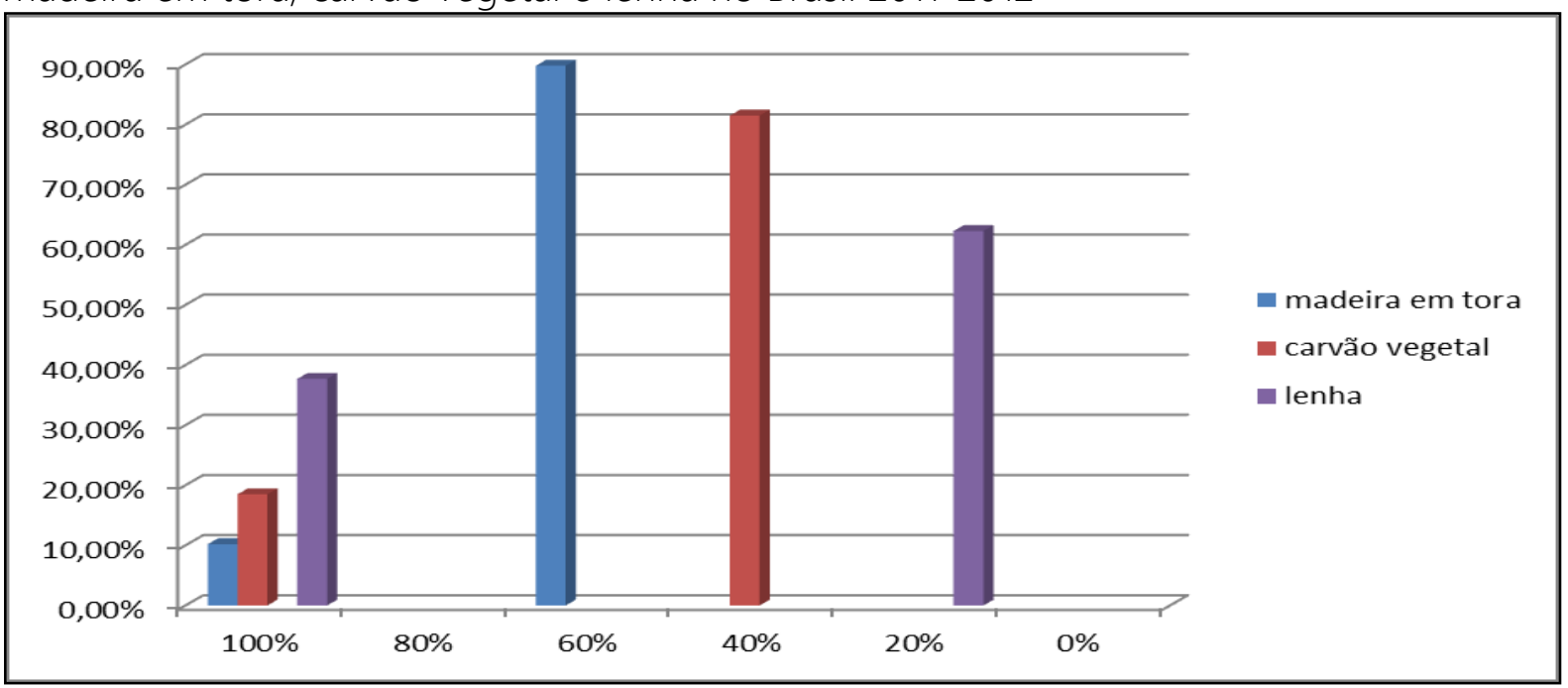

Fonte: IBGE, ano 2013.

No papel, a posição é o $9^{\circ}$ produtor mundial, com uma participação no comércio internacional menor que $2 \%$ no mesmo ano. Para os demais produtos, o volume de produção é significativo, mas com participação internacional incipiente. Com relação ao setor de siderurgia, tendo como insumo o carvão vegetal, o Estado é o $9^{\circ}$ maior produtor de ferro- gusa, mas a participação a nível mundial é inferior a 3\%, sem considerar que a participação do carvão vegetal na produção do ferro-gusa gira em torno de 24\%, como consta no CGEE (2014).

Em linhas gerais, tanto para economia brasileira como para a sociedade em geral, as florestas plantadas contribuem com uma parcela importante na geração 
de produtos, tributos, empregos e bemestar. Isto se deve, por se tratar de um setor estratégico no fornecimento de matéria-prima e produtos madeireiros e não madeireiros para exportação. Além de dispor esses produtos às florestas plantadas disponibiliza uma gama de serviços sociais e ambientais que vão desde a reabilitação de terras degradadas, o combate à desertificação do solo, seqüestro e armazenamento de carbono. Todavia, esta exploração florestal deve ser devidamente controlada, em termos de leis ambientais e órgãos fiscalizadores, só assim a Amazônia pode contribuir, acredita-se, muito mais na exploração deste recurso (NEGRÃO et al, 2015)

Do ponto de vista ambiental, a gestão responsável das florestas plantadas reduz as pressões sobre as florestas nativas para produtos florestais favorecendo a conservação e preservação dos recursos naturais (ABRAF, 2013). Adicioalmente, o Brasil é um país predominantemente florestal, pois os próprios dados nos indica isso: 463 milhões de hectares, ou $54,4 \%$ do território nacional, são cobertos por florestas naturais e plantadas, o que corresponde à segunda maior área florestal do planeta, atrás apenas da Rússia. Deste total, 456 milhões de hectares (98,5\%) correspondem a florestas naturais, sendo que 308 milhões de hectares $-67,5 \%$ das florestas naturais ou 36,2\% do território nacional - se referem a florestas públicas (federais, estaduais e municipais), o que ressalta a elevada importância do Estado na gestão deste patrimônio (ROMA e ANDRADE, 2013), dai a jsutificativa se produzir mais estudos sobre esta atividade.

No Pará, há em torno de 311 mil km² de terras com situação fundiária indefinida (terras publicas não arrecadadas, devolutas ou privadas), mesmo com potencial considerável, para que essas áreas venham ser usadas, é necessário que as terras sejam destinadas como Áreas Protegidas (IMAZON-SFB, 2011).

As Florestas Nacionais (Flonas) e Estaduais (Flotas) ofertam em torno de 64 mil km² (31\% de área necessária para manejo florestal) por meio de concessões florestais. Todavia, o manejo florestal comunitário para produção de madeira e 
produtos não madeireiros pode ocorrer em Reservas Extrativas (RESEX), Reservas de Desenvolvimento Sustentável (RDS), Terras Quilombolas e Projetos de Assentamento da Reforma Agrária (PA). Essas terras apresentam 22\% de área para manejo florestal e, as áreas privadas ocupam aproximadamente $21 \%$ do território legalmente permitido para a atividade florestal, embora, apenas 14\% (26 mil km²) dessas áreas estejam disponíveis para ofertar madeira nativa (IMAZON-SFB, 2011). Além disso, existem outras formas de levantar uma produção, que para Haffner et al (2016, p. 56), faz necessário levantar outras variáveis para tal computação de setor, a saber:

Os países, via de regra, adotam definições baseadas em uma ou mais das seguintes variáveis: número de empregados, valores das vendas, investimentos em ativos, tamanho do mercado, valor agregado, volume produzido, funções básicas da empresa e montante do capital investido.

Ostado do Pará é o principal estado produtor de madeira do país, com maior quantidade de floresta nativa, e uma produção anual de 6,6 milhões de metros cúbico de madeira nativa em tora. Em 2012 a produção de madeira em tora oriunda do extrativismo vegetal apresentou um aumento de 5,2\% em relação ao ano anterior. O Pará, com uma produção de (4 $877005 \quad m^{3}$ ) destacou-se, como um dos principais produtores frente aos demais estados amazônicos (IBGE-PEVS, 2012/2013).

O Pará, também, é destaque na produção lenha, tem a maior quantidade produzida $\left(3,1 \mathrm{mil} \mathrm{m}^{3}\right)$ e o segundo maior valor obtido com a extração (R\$72 milhões) em relação às demais unidades federadas, PEVS (2012). Além disso, a produção extrativa do Brasil constitui de diversificados produtos florestais madeireiros (lenha, carvão vegetal, madeira serrada, celulose, prod. Madeira processada) e não madeireiros (indústria química, indústria farmacêutica, indústria automobilística, indústria alimentícia), como constata SFB (2012).

Na Tabela 4, verifica-se a performance da produção da madeira em tora, extraída da produção florestal nativa. A média de produção de madeira em tora oriunda da floresta tropical, no período em análise (1990 a 2012) foi 31.7 milhões $\mathrm{m}^{3}$ e a região Norte 18, 6 milhões, portanto, com mais de $70 \%$ do total produzido deste produto. O Pará, da 
região Norte, contribuiu - em média, com $77 \%$. Em termos de taxa geométrica de crescimento, o Pará teve um decréscimo de 9,56\% ao ano, com significância estatística de 1\% de probabilidade de erro.

Isto se deve à reestruturação que este setor vem operando, principalmente a partir de 2002, quando as Leis
Ambientais e os órgãos de fiscalização, como o IBAMA, vem operando na região Norte, com destaque ao Pará. Isso Implica dizer que a região saiu de uma produção em 1990 de 40 milhões de m³ de madeira em tora, para aproximadamente 4,9 milhões de $\mathrm{m}^{3} \mathrm{em}$ 2012, como mostra o resultado desta pesquisa.

Tabela 4. Produção de madeira em tora no Brasil, Norte e Pará, m³: 1990, 1995, 2000, 2005,2010 e 2012.

\begin{tabular}{c|c|c|c}
\hline Anos & Brasil & Norte & Pará \\
\hline 1990 & 97.514 .108 & 80.825 .803 & 39.865 .963 \\
1995 & 61.588 .270 & 46.828 .504 & 43.919 .777 \\
2000 & 21.918 .527 & 12.639 .013 & 10.781 .501 \\
2005 & 17.372 .428 & 12.691 .252 & 9.935 .853 \\
2010 & 12.655 .284 & 8.549 .896 & 5.763 .823 \\
2012 & 14.925 .501 & 9.331 .807 & 4.877 .005 \\
\hline Média & 31.710 .345 & 22.770 .268 & 18.304 .948 \\
\hline Desvio Padrão & 22.511 .676 & 18.574 .016 & 14.342 .707 \\
\hline Coef.Var(\%) & 70,99 & 81,57 & 78,35 \\
\hline
\end{tabular}

Fonte: Elaboração própria a partir dos dados do IBGE (2013).

Ademais, esse tipo de situação implicou numa variação negativa de $88 \%$ entre 1990 a 2012, em 23 anos. Na Figura 4, visualiza-se melhor este decréscimo na quantidade de madeira produzida no estado do Pará. Em termos regionais, estudos realizados pelo IMAZON revelaram que de 2009 a 2013, a exportação dos principais produtos florestais madeireiros somaram em valores nominais $\mathrm{R} \$ 38.248 .544$ milhões do valor produzido, dos quais $\mathrm{R} \$ 42.766$ foi de madeira em tora. 
Figura 4. Produção, em metros cúbicos, de madeira em tora no estado do Pará: 1990 a 2012.

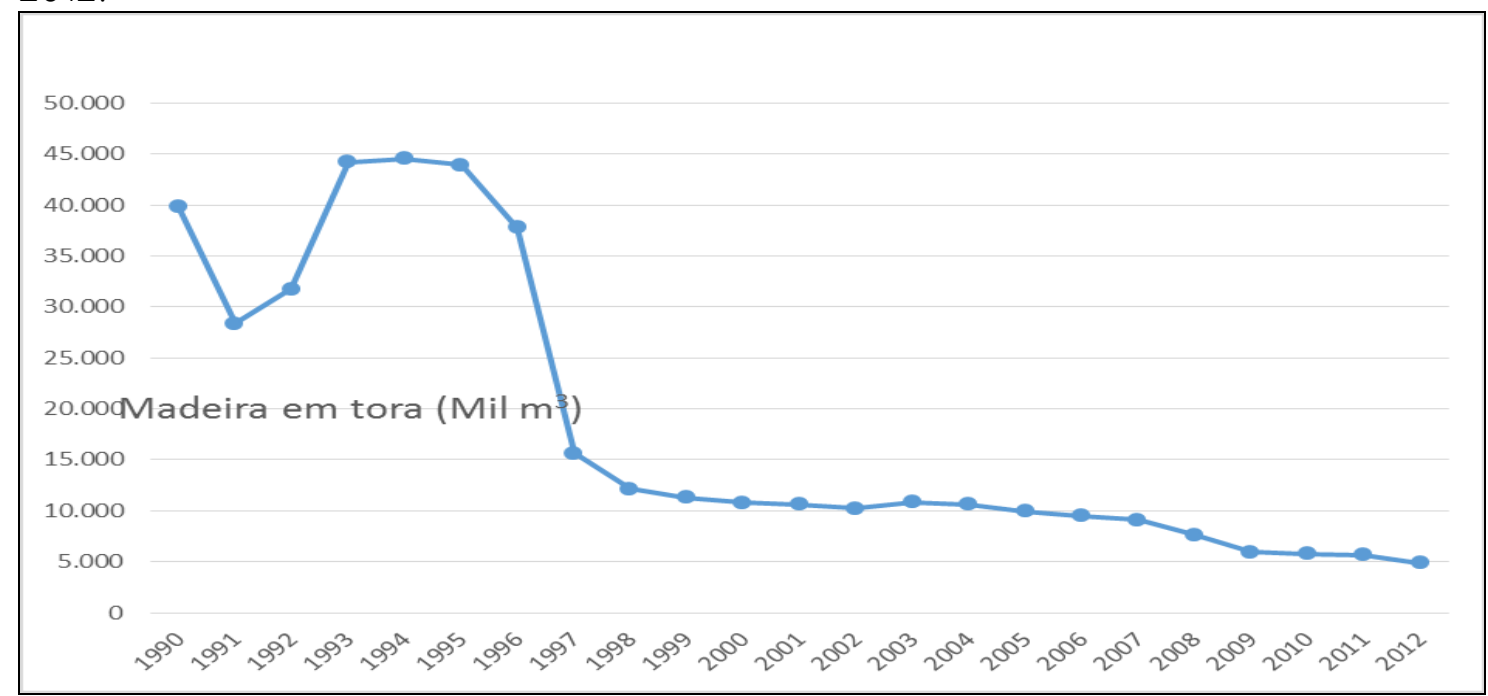

Fonte: IBGE (2013).

No Estado do Pará a produção do setor madeireiro caiu 40\% de 11,2 milhões de $\mathrm{m}^{3}$ Seus pólos madeireiros mais expressivos foram Paragominas, Tailândia, Tomé-Açú e Ulianópolis, logo em seguida vêm à zona do Estuário Paraense, que atingiu o dispêndio de 13\% do volume de madeira na região metropolitana de Belém (IMAZON, 2012). Por conseguinte, especificamente através de índices de concentração visualizam-se os municípios produtores de madeira em tora.

ÍNDICES DE CONCENTRAÇÃO PARA O ESTADO DO PARÁ: ÍNDICE DE GINI LOCACIONAL

A produção de madeira em tora no estado do Pará, ainda permanece concentrada, conforme resultados do Índice de Gini Locacional (IGL) para o período de quatro anos analisados (1995, 2000, 2005 e 2012), cuja média foi de 0,86, conforme ilustra a Figura 5. O maior índice foi em 1995, com um IGL de 0,94, a partir, de 2000, 2005 e 2012, relativos aos anos analisados, o índice tem permanecido constante, ou seja, com 0,82, que equivale uma variação de negativa $12,77 \%$.

Observa-se que neste período houve forte retração na produção madeireira e começa a interferência nacional e internacional para diminuir a pressão sobre os usos de recursos naturais, incluindo a maior floresta tropical do mundo e, por isso, o país se organiza 
para programar normas e leis para diminuir a intensidade de exploração dos recursos amazônicos.

Percebe-se que a diminuição do IGL para 0,82 no último ano da série, podendo-se afirmar que a produção ainda é concentrada. Embora, pelo IGL não se consegue saber quais são os municípios que estão produzindo madeira em tora. Para isso, recorreu-se ao método do ICN.

Figura 5. Índice de concentração de produção de madeira em tora no Estado do Pará: 1995, 2000, 2005 e 2012.

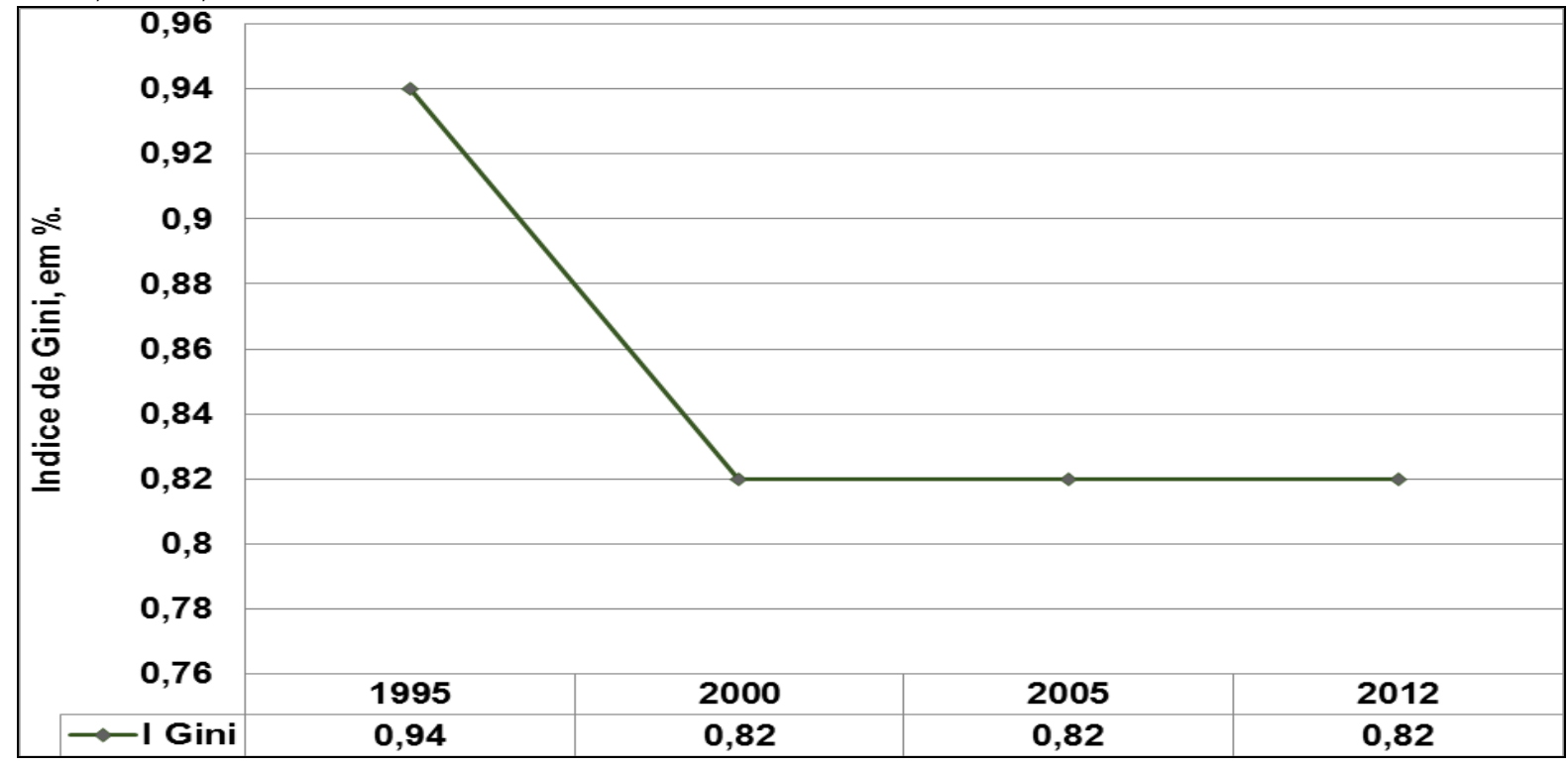

Fonte: elaboração dos autores, 2013.

ÍNDICE DE CONCENTRAÇÃO NORMALIZADO

Os municípios especializados na produção de madeira em tora foram aqueles que apresentaram a soma do Índice de Concentração Normalizado (ICN) médio mais um desvio padrão. Por este critério, a menor concentração de produção ocorreu em 2000, com 35 municípios e um ICN de 0,40 e a maior em 2005, com 44 municípios e um ICN de 0,34, conforme Tabela 5.

Em 1995 a produção de madeira em tora no estado do Pará foi 43,92 milhões de $\mathrm{m}^{3}$, que correspondia, em tese, a produção de 142 municípios. Entretanto com o ICN indicando que a produção deste produto estava concentrada em apenas 36 municípios, o que correspondia 25,35\% apenas. 
Tabela 5. ICN para a produção de madeira em tora nos 142 municípios paraenses: 1995, 2000, 2005 e 2012.

\begin{tabular}{ccccc}
\hline Ano & ICN & Desvio & ICN médio + Desvio Padrão & Número de Municípios Especializados \\
\hline 1995 & 0,1723 & 0,1339 & 0,3062 & 36 \\
2000 & 0,2257 & 0,1747 & 0,4005 & 35 \\
2005 & 0,1831 & 0,1548 & 0,3380 & 44 \\
2012 & 0,1985 & 0,1846 & 0,3832 & 42 \\
\hline
\end{tabular}

Fonte: Elaboração própria a partir de dados da PEVS. IBGE (2012).

Esses 36 municípios produziram 40,14 milhões de $\mathrm{m}^{3}$ de madeira em tora, sendo os cinco principais produtores, por ordem decrescente, Paragominas (13,83 milhões de $\left.\mathrm{m}^{3}\right)$, Ulianópolis $(10,99$ milhões de $\mathrm{m}^{3}$ ), Tomé Açu (4,12 milhões de $\mathrm{m}^{3}$ ), Dom Eliseu (2,33 milhões de $\mathrm{m}^{3}$ ) e Mãe do Rio (2,15 milhões de $\mathrm{m}^{3}$ ). Nestas condições, ao levar em consideração a produção de apenas estes cinco municípios, estes responderam pela produção total deste ano (1995) com 33,43 milhões de $\mathrm{m}^{3}$ ), que em termos relativos somavam 76,11\% da produção estadual.

No ano de 2000 a produção de madeira em tora reduziu de 43,92 milhões de $m^{3}$ para 10,78 milhões de $m^{3}$ o representou uma queda brutal de $307,72 \%$, ou ainda, o equivalente a mais de 3,5 vezes a quantidade produzida. De qualquer modo, neste ano - pelo ICN - registrou uma especialização no produto em 35 municípios, que juntos 6,10 milhões de $\mathrm{m}^{3}$ - que correspondeu a $56,54 \%$.

Em linhas gerais, os cinco maiores produtores de madeira em tora, como resultado da pesquisa empírica, são (por ordem decrescente): Tailândia (800 mil $\mathrm{m}^{3}$ ), Portel $\left(750 \mathrm{mil} \mathrm{m}^{3}\right)$, Almeirim (651 mil $\mathrm{m}^{3}$ ), Redenção (496 mil m³) e Ipixuna do Pará $\left(455 \mathrm{mil} \mathrm{m} \mathrm{m}^{3}\right.$ ). Ou seja, a produção destes, foi de 3,15 milhões de $\mathrm{m}^{3}$ que somaram 29,24\% da produção estadual. Registra-se, ainda que a queda na extração da madeira em tora foi devida a ação que o IBAMA iniciou ainda em 1999 e vai se estender até os dias atuais, de forma mais branda, talvez.

No ano de 2005 a produção de madeira em tora foi 9,94 milhões de $\mathrm{m}^{3}$, portanto com baixa redução se comparado ao ano de 2000, ou seja, 
redução de apenas 7,79\%. Quanto aos municípios especializados, somaram-se 44, com uma produção de 8,59 milhões de $\mathrm{m}^{3}$ de madeira em tora, que correspondia a $86,48 \%$ do total produzido no Pará. Ademais, dos cinco municípios com maior produção neste ano, foram: Tailândia (1,4 milhão de $\mathrm{m}^{3}$ ) Portel $(950$ mil m³), Paragominas (826 mil $\mathrm{m}^{3}$ ), Baião (762 mil m³), Almeirim (568 mil $\left.\mathrm{m}^{3}\right)$, que somados corresponderam a $45,37 \%$ do total de madeira em tora no Estado do Pará.

Em 2012, a produção de madeira em tora no estado do Pará totalizou em 4,87 milhões de $\mathrm{m}^{3}$, isto implicou em uma redução de 51\% em relação a 2005, cuja produção foi de 9,94 milhões de $\mathrm{m}^{3}$. Mas, de qualquer modo, 29,58\% municípios produziram madeira em tora, que corresponde 42. Destes, os cinco maiores em termos de produção, foram em ordem decrescente: Portel (900 mil $\left.\mathrm{m}^{3}\right)$, Almeirim $\left(506 \mathrm{mil} \mathrm{m}^{3}\right.$ ), Paragominas (287 mil $\left.\mathrm{m}^{3}\right)$, Santarém (242 mil $\left.\mathrm{m}^{3}\right)$, Tomé-Açu (177 mil m³), totalizando 2,11 milhões de $\mathrm{m}^{3}$, ou seja, 43,36\% da produção de madeira em tora no estado do Pará.
O resultado do ICN foi o seguinte: existem municípios que figuram em apenas uma vez, nos quatro anos, é que municípios especializados apenas uma vez (Ulianópolis, Dom Eliseu, Mãe do Rio, Redenção, Ipixuna do Pará e Santarém), outros que foram especializados em duas ocasiões (Tomé Açu, Tailândia) e os que se apresentaram especializado em três anos, foram: Paragominas, Portel Almeirim.

Vale, ainda, ressaltar se somar as produções nos anos especializados, Paragominas foi o que mais se destacou na produção de madeira em tora $(14,94$ milhões de $\mathrm{m}^{3}$ ) e em, segundo, Portel com 2,6 milhões de $\mathrm{m}^{3}$. Por fim, o município de Almeirim com 1,73 milhões de $\mathrm{m}^{3}$. Com esses resultados, é possível vislumbrar possibilidades de políticas públicas de manejo para estas áreas que ainda possuem alto impacto de retirada de madeira em tora.

\section{CONCLUSÃO}

O mercado de madeira em grande escala, quer seja em sua forma bruta ou beneficiada em diversos tamanhos, laminada, compensada, prensada e 
transformada em objetos úteis é dinâmico e ao mesmo tempo polêmico devido ao controle quanto à exploração racional dos recursos madeireiros de origem tropical que vem ocorrendo. Por conta disto, qualquer tomada de decisão no que pertence á intervenção do setor, provoca questionamentos diversos por parte dos defensores. Entretanto, ressalte-se que no Sul e Sudeste do páis já há granes investimentos para a exploração da madeira plantada (silvicultura).

Embora este estudo, mediante os levantamento bilbiográficos e dos dados apurados, os resultados indicam que o produto madeireiro tem uma participação relevante para economia do país no que diz respeito à exportação da matéria-prima, que adiciona valores para os produtos e como retorno influencia o crescimento econômico para as regiões periféricas, como o Norte.

Por isso, com a exploração devidamente controlada, em termos de leis ambientais e órgãos fiscalizadores, a Amazônia pode contribuir, acredita-se, muito mais na exploração deste recurso, principalmente o Pará, dado o estoque natural da matéria - prima (floresta tropical) .

Quant ao setor madeireiro, mais especificamente, fatos importantes de agregação de valor, geração de renda, ocupação, devem sempre ser em considerados, tanto no que diz respeito a políticas públicas quanto em políticas públicas, porém, não se deve esquecer que isto exige investimentos, seja na aquisição de capitação fixo, seja no treinamento de mão-de-obra, etc. atualmente, o que se vê é mais em termos de fiscalização contra a exploração ilegal, embora esta não tenha acabado, como diversos estudos já apontaram e anteriormente citados. Mas, por estes resultados, mostrou que se deve investir em outro lado, do conhecimento e da tecnologia, assim como a gestão desses recursos.

Ademais, é importante destacar que o Brasil possui uma posição de destaque extraordinário no mercado mundial de produtos florestais com ostentação na geração de valor do segmento de celulose e papel, o que deriva de sua riqueza dos recursos naturais, no caso a floresta tropical. Apesar de outros países 
de maior tradição florestal, como Estados Unidos, Canadá e Finlândia, estarem mais bem colocados no ranking em termos de volume total da produção.

Por tudo isso, o Brasil é considerado referência internacional por suas práticas sustentáveis e por ter quase a totalidade de seus produtos procedentes de plantios florestais, apontados por setores deste segmento brasileiro. Por outro lado, no modelo de índices de concentração, constatou-se que a produção de madeira em tora no Estado do Pará continua concentrada, com o IGL médio alto de 0,85 no período de quatro analises, pelo emprego do ICN, averiguou-se que esta produção ocorre de forma especializada, em 39 municípios paraenses

Cabe frisar, finalmente, que estes resultados, destaca-se da importância desta metodologia para conhecimento e emprego de políticas públicas que devem ser direcionadas ao setor florestal e, possam se alocar melhor os recursos produtivos escassos (financiamento, mão-de-obra especializada, gestão compartilhada entre atores produtivos). Com isto, ganhar eficiência produtiva que resultem em desenvolvimento local sustentável, com geração de emprego e renda estadual.

\section{REFERÊNCIAS}

ABRAF - ASSOCIAÇÃO BRASILEIRA DE PRODUTORES DE FLORESTAS PLANTADAS. Anuário Estatístico 2013 ano base 2012. - Brasília: ABRAF 2013.

ÂNGELO, H. ALMEIDA, A. N. de.; SERRANO, A. L. M. Determinantes da demanda de madeira em toras para celulose no Brasil. Sci. For., Piracicaba, v. 37, n. 84, p. 491-498, dez. 2009.

BRITO, B.; SANTOS, P.; THUAULT, A. A Governança de fundos ambientais e florestais na Amazônia Legal. Belém PA. IMAZON, 2014, 58 p.

\section{CGEE - CENTRO DE GESTÃO E ESTUDOS ESTRATÉGICOS.} "Levantamento dos níveis de produção de aço e ferro-gusa, cenário em 2020 Ênfase: Usos da energia gerada na combustão dos gases da carbonização". Subsídios 2014 ao Plano Siderurgia do MDIC: Modernização da Produção do Carvão Vegetal. 2014. Disponivel em:<http://www.cgee.org.br/eventos/arq uivos/CarvaoVegetal-CGEE NTproducao de aco e gusa2.pdf.>. Acesso em: 10 mai. 2017.

CHIAPINOTO, F. V.; MARION FILHO, P. J.; CORONEL, D. A.; BENDER FILHO, R. Concentração e o Poder de Mercado no Setor de Telefonia Móvel Brasileiro (2009-2014). Revista Eletrônica de Administração e Turismo (ReAT), v. 10, n. 05, Janeiro/Junho, 2017. 
EFIATLANTIC - ATLANTIC EUROPEAN REGIONAL OFFICE OF THE EUROPEAN FOREST INSTITUTE. Summary Report Aof the 3rd International Congress on Planted Forests. 2013. Disponível em: $\leq \mathrm{http} /$ goo.gl2VXpv2 $>$. Acesso em 12/01/2016.

ESQUIVEL, R. M.; SENNA, V; GOMES, G. S. S. Análise Espectral Singular: Comparação de Previsões em Séries Temporais. Revista ADM.MADE, Rio de Janeiro, Ano 12, v. 16, n. 2, p. 87-101, maio/setembro, 2012.

FAO - FOOD AND AGRICULTURE ORGANIZATION OF THE UNITED NATIONS. Planted forests in sustainable forest management: a statement of principles. FAOSTAT - FOOD AND AGRICULTURE ORGANIZATION CORPORATE STATISTICAL DATABASE 2014. Disponível em: <http://faostat3.fao.org/faostat-

gateway/go/to/download/F/FO/E>. Acesso: 14/01/2017.

FILGUEIRAS, G. C.; MOTA JUNIOR, J. K.; SILVA, R. P. da; BENTES, E. S. Análise e perspectivas para o desenvolvimento da silvicultura no Estado do Pará. Amazônia: Ci. \& Desenv., Belém, v. 7, n. 13, jul./dez. 2011.

FONTE, T.T. F. da; CALIL JÚNIOR, C. Pontes protendidas de madeira: alternativa técnico-econômica para vias rurais. Eng. Agríc., Jaboticabal, v. 27, n. 2, p. 552-559, maio/ago. 2007.

GREENPEACE. RELATÓRIO ANUAL 2001. Disponível:<

http://www.greenpeace.org/brasil/Global /brasil/report/anual/2001.pdf>. Acesso, Mar/2014.
HAFFNER, J. A.; SANTOS, L. T. dos; MENEZES, N. B. Micros, pequenas e médias empresas: atores importantes no espaço regional do Mercosul? Novos Cadernos NAEA, [S.I.], v. 19, n. 3, p. 51-70, dez. 2016.

HOMMA, A. K.O. Madeira na Amazônia: extração, manejo ou reflorestamento? Amazônia: Ci. \& Desenv., Belém, v. 7, n. 13, jul./dez. 2011.

IBGE - INSTITUTO BRASILEIRO DE GEOGRAFIA E ESTATÍSTICA Produção da extração vegetal e da silvicultura 2012; 2013.

LIMA, J. K. M.; ESPERIDIÃO, F. Uma análise dos Quocientes Locacionais das regiões brasileiras nos anos 1991, 2000 e 2010. Caderno de Ciências Sociais Aplicadas, N. 18, p. 175-196, 2014.

LIPPKE, B;. ONEIL, E.; HARRISON, R.; SKOG, K.; GUSTAVSSON, G.; SATHRe, R. Life cicle impacts of Forest management and wood utilization on carbon mitigation: nos and un nons. Carbon Management, v. 2, n. 3, p. 303-333, 2011.

NEGRÃO, K. R. M.; GOMES, S. C.; CABRAL, E. R.; CARVALHO, M. C. S. Revista de Gestão e Tecnologia/NAVUS. Florianópolis-SC, v. 5, n. 4, p. 06-20, out./dez., 2015.

PETRAUSKI, S. M. F. C.; MARQUES, G. M.; SILVA, M. L.; CORDEIRO, S. A.; SOARES, N. S. Competitividade do Brasil no mercado internacional de madeira serrada. Cerne, v. 18, n. 1, p. 99-104, 2012.

PIRRAGLIA, A.; GONZALEZ, R., DENIg; J., SALONI, D.; WRIGHT, J. Assessment of the most adequate pretreatments and 
woody biomass sources intended for direct co-firing in the U.S. BioResources, v. 7, n. 4, p. 4817-4842, 2012.

PLANTED FORESTS IN SUSTAINABLE FOREST MANAGEMENT: a statement of principles - 201Sul0, 2009. Disponível em: www.fao.org.br/forestry/plantedforests. Acesso em: 14/01/2017.

POLDER, M. E. V.; DIRK, B. van den; Pijll, E. van der. "Micro and macro indicators of competition: comparison and relation with productivity change". Discussion paper 09024. Statistics Netherlands, The Hague/Heerlen, 2009.

Produção da Extração e da Silvicultura PEVS 2012; 2013. Disponível em: < http://www.ibge.gov.br/home/estatistica/ economia/pevs/2012/>. Acesso em: 06 jun. 2017.

REFLORE-MS - Associação sul-matogrossense produtores e Consumidores de Florestas Plantadas Dezembro de 2017. Disponível em:< http://www.reflore.com.br/ arquivos/dive rsos/revista-msflorestal-dez2013.pdf>.

Acesso em: 14/01/2017.

REMADE - Revista da Madeira. A retomada das exportações brasileiras de produtos da madeira. REMADE, Rio Grande do Sul. Ano: 26; edição 147, Disponível: www.remade.com.br. Acesso: 14/01/2017.

ROMA, J. C.; ANDRADE, A. L. C. de. Economia, Concessões florestais e a Exploração sustentável de madeira. Boletim regional, urbano e ambiental | 08 | jul.-dez. 2013.
SAE/PR - SECRETARIA DE ASSUNTOS ESTRATÉGICOS DA PRESIDENCIA DA REPÚBLICA. Florestas Plantadas: Base para a Política Nacional, 2014. Disponível em: $\quad<$ http://www.sae.gov.br/site/wpcontent/uploads/notaT\%C3\%A9cnicaSAE -1.pdf>. Acesso em: 14/01/2017.

SANTANA, A. C.; SANTOS, M. A. S. dos. ; OLIVEIRA, C. M. Preço da madeira em pé, valor econômico e mercado de madeira nos contratos de transição do Estado do Pará. Relatório de Pesquisa. Belém - Pará; UFRA/IDEFLOR, 2010.

SANTANA, A. C. de.; SANTOS, M. A. S. dos. SANTANA, Á. L. de.; 4 YARED, J. A. G. $O$ valor econômico da extração manejada de madeira no Baixo Amazonas, estado do Pará. Revista Árvore, Viçosa-MG, v.36, n.3, p.527-536, 2012.

SFB-SERVIÇO FLORESTAL BRASILEIROFlorestas do Brasil em resumo 2013Brasília: Serviço Florestal Brasileiro 2013 188p. Disponível em: <http://goo.gl/u5xbJr>. Acesso em: 14/01/2017.

SFB - SERVIÇO FLORESTAL BRASILEIRO; IMAZON - INSTITUTO DO HOMEM E MEIO AMBIENTE DA AMAZÔNIA. A atividade madeireira na Amazônia Brasileira: produção, receita e mercado. Brasilia: SFB: IMAZON, 2011.

SOARES, N.S.; SILVA, M.L. Competitividade Brasileira no Comércio Internacional de Produtos Extrativos Vegetais. Revista Econômica do Nordeste, v. 44, n. 4, p. 879-893, 2013. 